\title{
INTERNATIONAL WORKSHOP
}

\section{The Role of the Biopharmaceutics Classification System and IVIVC in the Approval of Oral Drug Products}

In March 1998, a workshop with the title "The Role of the Biopharmaceutics Classification System and In Vitro-In Vivo Correlations in the Approval of Oral Drug Products" will be beld in Frankfurt, Germany under the co-sponsorship of AAPS and APV in cooperation with CRS, EUFEPS and the FDA. This workshop is intended to provide a forum for discussion of current tbinking in the FDA and the European regulatory authorities and industry in respect to the requirements for bioequivalence studies and when in vitro tests can be used as a surrogate for studies in man. Similar to a previous workshop beld in Washington, D.C. in April, 1997, the first day will focus on appropriate study design and data analysis for implementing the BCS and its relevance to bioequivalence studies. The second day will focus on appropriate study design and data analysis for implementing the BCS and achieving in vitro / in vivo correlations. The third day will be devoted to a discussion of the regulatory issues, with presentations by members of the FDA on the current guidances in this area as well as commentary on international perspectives and barmonization of regulations from representatives of key European organizations such as the European Medicines Evaluation Agency, WHO, the German authorities (BfARM) and the European Pharmacopeia.

The workshop Committee consists of Jennifer Dressman, Ph.D., Co-Chair (University of Frankfurt), Hans Lennernäs, Pb.D., CoChair (University of Uppsala), Gordon Amidon, Ph.D. (University of Michigan), Luc Balant, Ph.D. (University of Geneva), Henning Bhume, Pb.D. (German Pharmacists' Central Laboratory), Robert Gurny, Pb.D. (University of Geneva), Vinod Shab, Ph.D. (FDA), and Roger Williams, M.D. (FDA). We look forward to providing a forum for the participants to deepen their understanding of issues important to bioequivalence and to lively discussion of application of the BCS concepts on the European scene.

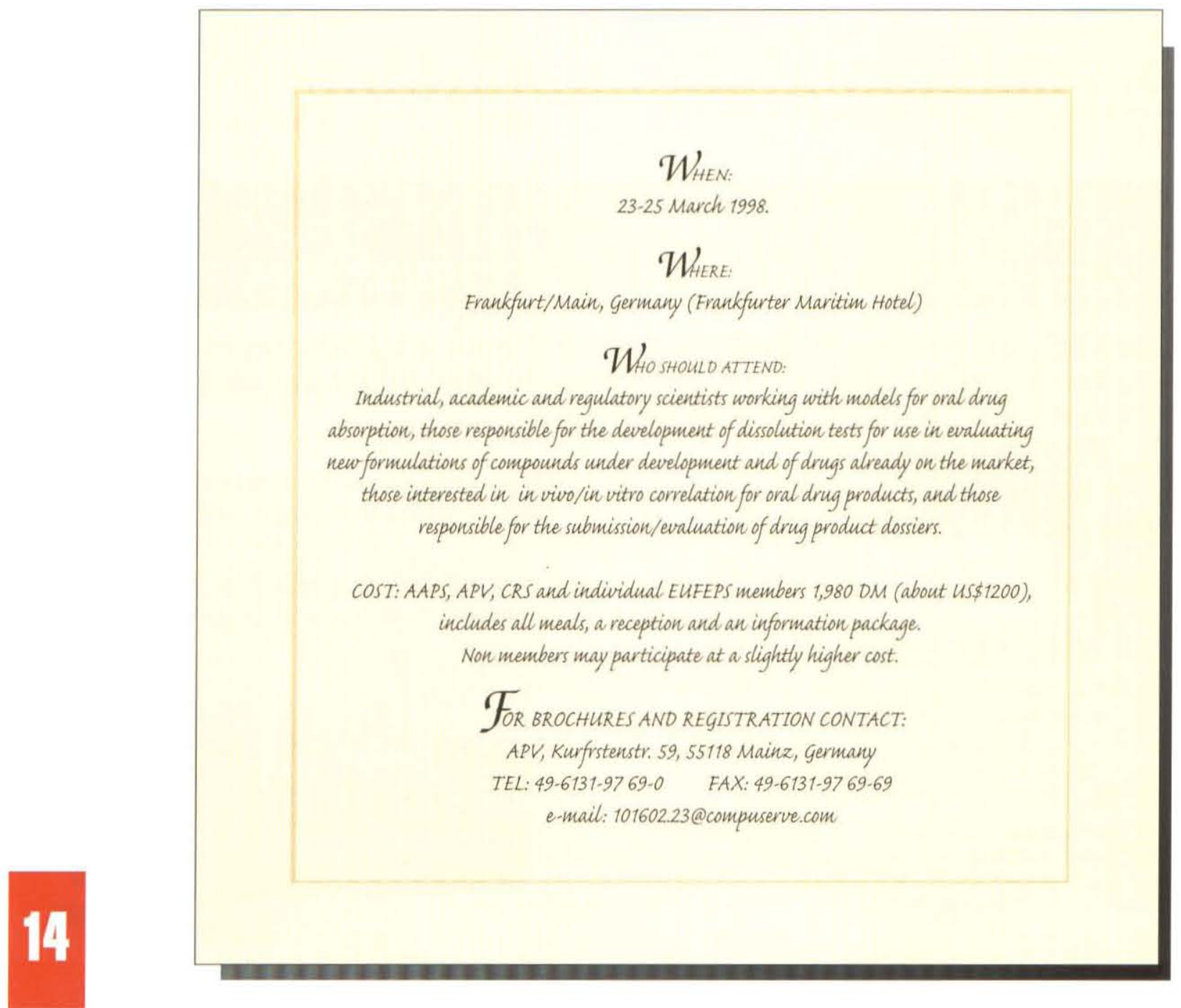

